\title{
Relation of RV Function to Presence and Degree of Systemic Hypertension
}

\author{
Adham Abdeltawab*, Inas Eweda, Ahmad Elsayed Mostafa, Peter Demian and Omar Awwad
}

Faculty of Medicine, Department of Cardiology, Ain Shams University, Egypt

\begin{abstract}
Hypertension is an important non-communicable disease in Africa. It is the most important cardiovascular risk factor. The effect of hypertension on left ventricle has been documented for long time, but sparse and consistent evidence shows an impact of hypertension on the right ventricle. The RV can be studied with many imaging and functional modalities. In clinical practice, echocardiography is the mainstay of evaluation of RV structure and function. Aim of this study was to analyze impact of presence and severity of systemic arterial hypertension (HTN) on right ventricular function measured by tissue Doppler echocardiography. For this aim we included sixty consecutive patients from outpatient clinics and thirty healthy age and sex matched individuals and made a full 2D and tissue doppler study for the RV and compared results for non-hypertensives, stage 1 and stage 2 hypertensives. Doppler data obtained at the tricuspid valve showed statistically significant results regarding $\mathrm{E}$, E/A, DT and IVRT correlating the presence and degree of hypertension with RV diastolic function $(p<0.001)$. The current study demonstrated that RV diastolic dysfunction not only is an early marker that is correlated to presence of systemic arterial hypertension but also showed it to be a marker of its severity and degree of control as conveyed by stage of hypertension.
\end{abstract}

Keywords: Hypertension; Right ventricle; Tissue doppler; Systolic function; Echocardiography

\section{Introduction}

Hypertension is the single greatest cause of long-term healthcare in Europe [1]. Hypertension is an important non-communicable disease in Africa. It is the most important cardiovascular risk factor [1-4]. It has become clear that hypertension begins in childhood and adolescence, and that it contributes to the early development of cardiovascular diseases. But recent US studies reported that hypertension is underdiagnosed in these groups [5].

Hypertension is the most important risk factor for death in industrialized countries. It increases hardening of the arteries thus predisposes individuals to heart disease, peripheral vascular disease and strokes, also hypertensive retinopathy and hypertensive nephropathy [4].

The effect of hypertension on left ventricle has been documented for long time, but sparse and consistent evidence shows an impact of hypertension on the right ventricle [6]. The RV can be studied with many imaging and functional modalities. In clinical practice, echocardiography is the mainstay of evaluation of RV structure and function. Tricuspid annular plane systolic excursion (TAPSE) is a useful quantitative measurement of RV systolic performance. Strain and Strain rate are newer techniques for studying regional contractility [7]. The most extensively investigated area of potential RV dysfunction is coronary artery disease, where RV ejection fraction has been measured in patients with and without the right coronary artery occlusion [8]. Furthermore, patterns of RV asynergy have been evaluated in acute [9] and chronic [10] ischemic coronary disease. Attempts have been also made to determine the extent of RV dysfunction in chronic obstructive pulmonary disease and adult congenital heart disease with RV pressure and volume overload, [11] and to compare these findings with the results in normal adult population.

Very little is known, however, about the nature of RV performance when the left ventricle is exposed to a chronic pressure overload that takes place in essential hypertension. Because the distortions of the normal geometry of the two ventricles influence each other's performance. Hypertension is classified as being primary, of no identifiable cause and less commonly secondary hypertension of identified cause.

\section{Objective}

Aim of this study was to analyze impact of presence and severity of systemic arterial hypertension (HTN) on right ventricular function measured by tissue Doppler echocardiography.

\section{Methods}

\section{Patient selection}

The study included sixty consecutive patients from outpatient clinics and thirty healthy individuals. Healthy control persons were age and sex matched and the study took place during the period from January to June 2014. The HTN diagnosis was confirmed according to the JNC 7 guidelines for diagnosis of HTN [12]. Patients were classified into two groups, one with stage I hypertension where systolic blood pressure (SBP) was $140 \mathrm{mmHg}-159 \mathrm{mmHg}$, or diastolic blood pressure (DBP) was $90 \mathrm{mmHg}-99 \mathrm{mmHg}$. The other group was that of stage II hypertension where SBP $\geq 160 \mathrm{mmHg}$, or DBP $\geq 100 \mathrm{mmHg}$ [12].

Before inclusion, an informed written consent was obtained from each patient after full explanation of the study protocol, and the protocol was reviewed and approved by our local institutional human research committee as it conforms to the ethical guidelines of the 1975 Declaration of Helsinki, as revised in 2002. The exclusion criteria included ischemic, rheumatic and congenital heart disease. Patients suffering from atrial fibrillation, impaired left ventricular systolic function $(\mathrm{EF}<50 \%)$, advanced lung disease and patients with pulmonary hypertension were also excluded.

${ }^{*}$ Corresponding author: Adham Abdeltawab, Faculty of Medicine, Departmen of Cardiology, Ain Shams University, Egypt, Tel: 201008800788; E-mail: adham_abdeltawab@med.asu.edu.eg, adham1st@yhoo.com

Received January 13, 2018; Accepted January 25, 2018; Published January 29 2018

Citation: Abdeltawab A, Eweda I, Mostafa AE, Demian P, Awwad O (2018) Relation of RV Function to Presence and Degree of Systemic Hypertension. J Cardiovasc Dis Diagn 6: 306. doi: 10.4172/2329-9517.1000306

Copyright: (c) 2018 Abdeltawab A, et al.. This is an open-access article distributed under the terms of the Creative Commons Attribution License, which permits unrestricted use, distribution, and reproduction in any medium, provided the original author and source are credited. 


\section{Echocardiography}

This was performed to all subjects according to the same protocol with use of GE Medical Systems Vivid 7 ultrasound machine equipped with $2 \mathrm{M} \mathrm{Hz}-4 \mathrm{M} \mathrm{Hz}$ sector transducer probe. Routine echocardiography with the standard projections was done initially and followed by doppler flow tracing registration at the level of mitral and tricuspid valves. All echo-doppler measurements were analyzed by the average of five cardiac cycles, to minimize difference during the breath cycles. Parameters obtained through parasternal approaches in the M-mode projection were analyzed: left ventricular end diastolic diameter (EDD), left ventricular end systolic diameter (ESD), interventricular septum (IVS), left ventricular posterior wall thickness (PW), aortic root dimension (Ao) and left atrial diameter (LA). The assessment of the left ventricular systolic function consisted of shortening fraction (FS\%), left ventricular ejection fraction (EF\%) obtained according to Simpson's formula.

The right ventricle was assessed in the apical four-chamber view by measuring basal, mid-cavity and longitudinal dimensions. The right ventricular lateral wall thickness was also measured in this view. Right ventricular global systolic function was assessed as tricuspid annular plane systolic excursion (TAPSE), which was acquired by placing M-mode cursor through the tricuspid annulus in the standard apical four-chamber window and measuring the amount of longitudinal motion of the annulus at peak systolic, TAPSE is a method to measure the distance of systolic excursion of the right ventricular annular segment along its longitudinal plane.

In order to assess the left ventricular diastolic function, the isovolumetric relaxation time (IVRT) (ms) which was the interval from the aortic valve closure signal to the mitral valve opening signal and the following transmitral inflow parameters were measured (pulsed wave Doppler registration with gate placed at the tip of open mitral valve leaflets): peak velocity of the early E-wave transmitral flow (E) (m/ $\mathrm{sec})$, peak velocity of late A-wave transmitral flow $(\mathrm{A})(\mathrm{m} / \mathrm{sec})$, and the ratio (E/A) was derived. The duration of both $\mathrm{E}$ and $\mathrm{A}$ waves was also measured in (ms). The deceleration time (DT) (ms) the deceleration of the early diastolic transmitral flow was also obtained.

The right ventricular global filling measurement was determined as $\mathrm{E}$ and $\mathrm{A}$ peak velocities $(\mathrm{m} / \mathrm{sec}), \mathrm{E} / \mathrm{A}$ ratio, $\mathrm{E}$ wave deceleration time $(\mathrm{ms})$ and right ventricular isovolumetric relaxation time (ms) which was measured as the time interval from the end of pulmonary outflow to the onset of tricuspid inflow.

\section{Tricuspid annular velocity by DTI}

We used the same GE Vivid Seven machine using a commercially available imaging system equipped with a 2-4 MHZ transducer and secondary harmonic imaging to optimize endocardial border visualization. From the apical four chamber view, the longitudinal tricuspid annular velocities were recorded from lateral right ventricular site using PW-DTI. The values from the above site were used to assess global systolic and diastolic function. Three major velocities were considered: the positive peak systolic velocity when the tricuspid ring moved towards the cardiac apex due to longitudinal contraction of the $\mathrm{RV}$ and two negative diastolic velocities when the tricuspid annulus moved towards the base away from the apex, one during the early phase of diastole and the other in the late phase of diastole. A mean of five consecutive cycles was used to calculate all echo-Doppler parameters.

\section{Statistical analysis}

Data was presented as mean $\pm \mathrm{SD}$. The $X^{2}$ test was used to compare differences between proportions. ANOVA test was used for analysis of continuous data. A Post Hoc was performed to the data with $\mathrm{p}<0.05$ by ANOVA test. A probability value of $\mathrm{p}<0.05$ was considered statistically significant. Analyses were performed with SPSS version 12.0 statistical package (SPSS Inc., Chicago, IL, USA). Differences were considered significant if the null hypothesis could be rejected at the 0.05 probability level.

\section{Results}

The study included 90 patients with a mean age of $48.57 \pm 6.82$. There was no significant statistical difference between the three studied groups (non-hypertensives, stage I hypertensives and stage II hypertensives) as regards age, sex, RV function measured by TAPSE, and other echocardiographic data obtained by $2 \mathrm{D}$ and M-mode. The IVS and PW thickness measurements were found to be significantly higher in patients with stage II hypertension when compared to stage I HTN and control groups, $(\mathrm{p}<0.001)$. Doppler data obtained at the tricuspid valve showed statistically significant results regarding E, E/A, DT and IVRT correlating the presence and degree of hypertension with RV diastolic function $(p<0.001)$. Similarly, significant values were found in post-Hoc analysis with LSD test. Comparing DTI measurements at the right ventricular tricuspid annulus in the control, stage I HTN vs. Stage II HTN, statistically significant values for S, $E^{\prime}$ measurements $(\mathrm{p}<0.001)$ were found. Significant values were also found in post-Hoc analysis between the 3 groups with LSD test (Tables 1-5).

\section{Discussion}

Aim of the current study was to analyze impact of presence and severity of systemic arterial hypertension (HTN) on right ventricular

\begin{tabular}{|c|c|c|c|c|c|}
\hline \multirow[t]{2}{*}{ Variables } & \multirow{2}{*}{$\begin{array}{c}\text { Control } \\
\text { Mean } \pm \text { SD }\end{array}$} & \multirow{2}{*}{$\begin{array}{l}\text { Stage I HTN } \\
\text { Mean } \pm \text { SD }\end{array}$} & \multirow{2}{*}{$\begin{array}{c}\text { Stage II HTN } \\
\text { Mean } \pm \text { SD }\end{array}$} & \multicolumn{2}{|c|}{$\begin{array}{l}\text { One Way } \\
\text { ANOVA }\end{array}$} \\
\hline & & & & $\mathbf{F}$ & p-value \\
\hline EF simpson's (\%) & $63.30 \pm 5.38$ & $66.67 \pm 5.47$ & $64.30 \pm 5.81$ & 2.901 & 0.06 \\
\hline LV EDD (mm) & $47.47 \pm 5.09$ & $49.00 \pm 5.29$ & $49.13 \pm 4.83$ & 1 & 0.372 \\
\hline LV ESD (mm) & $30.93 \pm 3.32$ & $30.80 \pm 4.38$ & $31.37 \pm 3.58$ & 0.184 & 0.833 \\
\hline IVS (mm) & $57 \pm 1.19$ & $10.33 \pm 1.18$ & $11.77 \pm 1.33$ & 24.399 & 0 \\
\hline $\mathrm{PW}(\mathrm{mm})$ & $10.17 \pm 0.95$ & $10.40 \pm 1.48$ & $11.90 \pm 1.47$ & 15.187 & 0 \\
\hline $\mathrm{RV}$ basal $(\mathrm{cm})$ & $2.92 \pm 0.05$ & $2.97 \pm 0.46$ & $3.05 \pm 0.54$ & 0.522 & 0.595 \\
\hline $\mathrm{RV}$ midcavity $(\mathrm{cm})$ & $2.34 \pm 0.47$ & $2.27 \pm 0.54$ & $2.37 \pm 0.50$ & 0.33 & 0.719 \\
\hline $\begin{array}{l}\text { RV longitudinal } \\
(\mathrm{cm})\end{array}$ & $4.96 \pm 0.77$ & $5.30 \pm 0$ & $5.09 \pm 0.88$ & 1.135 & 0.326 \\
\hline RV lateral wall $(\mathrm{cm})$ & $0.90 \pm$ & 2 & 25 & 2.924 & 0.059 \\
\hline TAPSE & $2.47 \pm 0.37$ & $2.48 \pm 0.42$ & $2.56 \pm 0.42$ & 0.45 & 0.639 \\
\hline
\end{tabular}

Table 1: Comparison between echocardiographic data obtained from echocardiographic study by $2 \mathrm{D}$ and $\mathrm{M}$-mode between the three studied groups.

\begin{tabular}{|c|c|c|c|c|c|}
\hline \multirow{2}{*}{$\begin{array}{c}\text { Right } \\
\text { ventricular }\end{array}$} & \multirow{2}{*}{$\begin{array}{c}\text { Control } \\
\text { Mean } \pm \text { SD }\end{array}$} & \multirow{2}{*}{$\begin{array}{c}\text { Stage I HTN } \\
\text { Mean } \pm \text { SD }\end{array}$} & \multirow{2}{*}{$\begin{array}{c}\text { Stage II HTN } \\
\text { Mean } \pm \text { SD }\end{array}$} & \multicolumn{2}{|c|}{$\begin{array}{l}\text { One Way } \\
\text { ANOVA }\end{array}$} \\
\hline & & & & $\mathbf{F}$ & p-value \\
\hline $\mathrm{E}(\mathrm{cm} / \mathrm{sec})$ & $59.07 \pm 6.78$ & $49.57 \pm 6.45$ & $46.00 \pm 7.07$ & 29.876 & 0 \\
\hline $\mathrm{A}(\mathrm{cm} / \mathrm{sec})$ & $47.70 \pm 6.45$ & $49.03 \pm 6.46$ & $51.17 \pm 11.23$ & 1.313 & 0.274 \\
\hline$E / A$ & $1.18 \pm 0.09$ & $1.00 \pm 0.10$ & $0.91 \pm 0.14$ & 42.642 & 0 \\
\hline E duration (ms) & $\begin{array}{c}160.27 \pm \\
45.91\end{array}$ & $\begin{array}{c}147.63 \pm \\
24.56\end{array}$ & $\begin{array}{c}181.20 \pm \\
19.88\end{array}$ & 8.329 & 0 \\
\hline A duration (ms) & $\begin{array}{c}129.00 \pm \\
25.87\end{array}$ & $101.63 \pm 6.13$ & $\begin{array}{c}105.53 \pm \\
11.81\end{array}$ & 23.306 & 0 \\
\hline DT (ms) & $\begin{array}{c}160.77 \pm \\
12.60\end{array}$ & $200.53 \pm 8.67$ & $203.43 \pm 8.10$ & 170.822 & 0 \\
\hline IVRT (ms) & $78.77 \pm 4.81$ & $86.97 \pm 5.80$ & $94.73 \pm 5.46$ & 66.178 & 0 \\
\hline
\end{tabular}

Table 2: Comparison between doppler data obtained at the tricuspid valve in the three studied groups by One Way ANOVA test. 


\begin{tabular}{|c|c|c|c|}
\hline Parameters & $\begin{array}{c}\text { Control vs } \\
\text { Stage I HTN }\end{array}$ & $\begin{array}{c}\text { Control vs } \\
\text { Stage II HTN }\end{array}$ & $\begin{array}{c}\text { Stage I vs } \\
\text { Stage II HTN }\end{array}$ \\
\hline $\mathrm{E}(\mathrm{cm} / \mathrm{sec})$ & 0 & 0 & 0.044 \\
\hline$E / A(\mathrm{~cm} / \mathrm{sec})$ & 0 & 0 & 0.002 \\
\hline E duration $(\mathrm{ms})$ & 0.132 & 0.014 & 0 \\
\hline A duration $(\mathrm{ms})$ & 0 & 0 & 0.371 \\
\hline DT $(\mathrm{ms})$ & 0 & 0 & 0.264 \\
\hline IVRT $(\mathrm{ms})$ & 0 & 0 & 0 \\
\hline
\end{tabular}

Table 3: Right ventricular data obtained by echo-Doppler analysed by Post-Hoc: LSD test.

\begin{tabular}{|l|c|c|c|c|c|}
\hline \multirow{2}{*}{ Variables } & Control & Stage I HTN & Stage II HTN & \multicolumn{2}{c|}{ One Way ANOVA } \\
\cline { 2 - 7 } & Mean \pm SD & Mean \pm SD & Mean \pm SD & F & p-value \\
\hline S (cm/sec) & $14.97 \pm 0.81$ & $12.37 \pm 0.72$ & $10.63 \pm 1.07$ & 185.588 & 0 \\
\hline E (cm/sec) & $16.93 \pm 1.17$ & $14.07 \pm 0.64$ & $12.17 \pm 0.75$ & 221.337 & 0 \\
\hline A (cm/sec) & $16.73 \pm 1.23$ & $17.47 \pm 1.07$ & $17.5 \pm 1.17$ & 4.195 & 0.018 \\
\hline
\end{tabular}

Table 4: Comparison between DTI data obtained at the right ventricular tricuspid annulus in the three studied groups by One Way ANOVA test.

\begin{tabular}{|c|c|c|c|}
\hline Parameters & $\begin{array}{c}\text { Control vs Stage } \\
\text { I HTN }\end{array}$ & $\begin{array}{c}\text { Control vs Stage } \\
\text { II HTN }\end{array}$ & $\begin{array}{c}\text { Stage I vs Stage } \\
\text { II HTN }\end{array}$ \\
\hline $\mathrm{S}(\mathrm{cm} / \mathrm{sec})$ & 0 & 0 & 0 \\
\hline $\mathrm{E}(\mathrm{cm} / \mathrm{sec})$ & 0 & 0 & 0 \\
\hline $\mathrm{A}(\mathrm{cm} / \mathrm{sec})$ & 0.016 & 0.012 & 0.912 \\
\hline
\end{tabular}

Table 5: Right ventricular tricuspid annular DTI analysed by Post-Hoc: LSD test.

function measured by tissue Doppler echocardiography. For that aim, sixty consecutive hypertensive patients presenting outpatient clinics and thirty age matched healthy individuals were recruited. In the 90 included subjects mean age was $48.57 \pm 6.82$. There was no significant statistical difference between the three studied groups (non-hypertensives, stage I hypertensives and stage II hypertensives) as regards age, sex, RV function measured by TAPSE, and other echocardiographic data obtained by 2D and M-mode. Ferlinz et al. [13] studied effects of systemic hypertension on right ventricular (RV) performance in 1980 by comparing catheter derived measurements of RV performance in 10 normal subjects to 20 patients with uncomplicated, asymptomatic essential hypertension (defined as cuff diastolic blood pressure $\geq 100 \mathrm{~mm} \mathrm{Hg}$ ). Cicala et al. [14] analyzed right ventricular longitudinal function in arterial systemic hypertension by pulsed tissue Doppler in 30 normotensives and 30 hypertensives, free of cardiac drugs. Akintunde et al. [15] intended to describe the impact of left ventricular pressure overload and hypertrophy due to hypertension on right ventricular morphology and function. One hundred subjects with systemic hypertension and 50 age- and gendermatched normotensive control subjects were used for this study. Twodimensional (2-D), M-mode and Doppler echocardiographic studies were done to evaluate the structure and function of both ventricles. Pedrinelli et al. [6] studied 98 subjects, 30 controls with optimal BP $(120 / 80 \mathrm{mmHg})$ and 68 individuals with high normal and mildly increased blood pressure referred for hypertension screening, to study right ventricular dysfunction by using tissue Doppler modality. Our study found the IVS and PW thickness to be significantly higher in patients with stage II hypertension when compared to stage I HTN and control groups, $(\mathrm{p}<0.001)$. Doppler data obtained at the tricuspid valve showed statistically significant results regarding E, E/A, DT and IVRT correlating the presence and the stage of hypertension with RV diastolic function $(\mathrm{p}<0.001)$. Comparing DTI measurements at the right ventricular tricuspid annulus in the control, stage I HTN vs. stage II HTN, statistically significant values for S, $\mathrm{E}^{\prime}$ measurements $(p<0.001)$ were found. These results agreed with other studies as recorded by Myslinski et al. [16], who mentioned that Right ventricular diastolic dysfunction had been observed in hypertensives in the majority of previous studies. Also, in a study by Tumuklu et al. [7], $\mathrm{E} / \mathrm{A}(\mathrm{RV})$ was not reduced in the hypertensive group $(1.19 \pm 0.21)$, but $\mathrm{RV}$ diastolic function was abnormal as demonstrated by TDI-derived velocities of right ventricular free wall and lateral tricuspid annulus ( $E^{\prime}$ was $13 \pm 2$, A' was $20 \pm 4$ ). This could be explained by their use of more sensitive and relatively load independent parameters indicating right ventricular diastolic dysfunction. Tissue Doppler E'/A' ratio less than one, indicated impairment of ventricular compliance more than the reversal of inflow E/A ratio [17].

Cicala et al. [14] found also that systemic hypertension is correlated to RV longitudinal diastolic dysfunction independent of its correlation with RV hypertrophy. Ferlinz et al. [13] demonstrated that right-sided circulation is not immune to the effects of systemic hypertension. The increase in the right-heart pressures among the essential hypertension patients was significantly different from the values in the normotensive controls. Akintunde et al. [15] concluded that systemic hypertension is associated with right ventricular morphological and functional abnormalities and that right ventricular diastolic dysfunction may be an early clue to hypertensive heart disease. Cittadini et al. [18] stated that right ventricular E/A ratio was strongly related to homologous left ventricular E/A ratio. Pedrinelli et al. [6] found that peak early $\mathrm{RV}$ diastolic and systolic velocities were reduced, and both correlated negatively to septal thickness and positively to homologous TDIderived left ventricular indices.

\section{Conclusion}

The current study demonstrated that RV diastolic dysfunction not only is an early marker that is correlated to presence of systemic arterial hypertension but also showed it to be a marker of its severity and degree of control as conveyed by stage of hypertension.

\section{References}

1. Cooper RS, Rotimi CN, Kaufman JS, Muna WF, Mensah GA (1998) Hypertension treatment and control in sub-Saharan Africa: the epidemiological basis for policy. BMJ 316: 614-617.

2. Kadiri S (2005) Tackling cardiovascular disease in Africa. BMJ 331: 711-712.

3. Opie LH, Mayosi BM (2005) Cardiovascular disease in sub-Saharan Africa Circulation 112: 3536-3540.

4. Kuller LH (2007) Epidemic hypertension in Sub-Saharan Africa. Hypertension 50: $1004-1005$.

5. Mattoo TK (2010) Hypertension in pediatric patients. Indian Pediatr 47: 473-474

6. Pedrinelli R, Canale ML, Giannini C, Talini E, Dell'Omo G, et al. (2010) Abnormal right ventricular mechanics in early systemic hypertension: a twodimensional strain imaging study. Eur J Echocardiogr 11: 738-742.

7. Tumuklu MM, Erkorkmaz U, Ocal A (2007) The impact of hypertension and hypertension-related left ventricle hypertrophy on right ventricle function. Echocardiography 24: 374-384.

8. Johnson LL, McCarthy DM, Sciacca RR, Cannon PJ (1979) Right ventricula ejection fraction during exercise in patients with coronary artery disease. Circulation 60: 1284-1291.

9. Sharpe DN, Botvinick EH, Shames DM, Schiller NB, Massie BM, et al. (1978) The noninvasive diagnosis of right ventricular infarction. Circulation 57: 483-490.

10. Ferlinz J, Delvicario M, Gorlin R (1976) Incidence of right ventricular asynergy in patients with coronary artery disease. Am J Cardiol 38: 557-563.

11. Gentzler RD, Briselli MF, Gault JH (1974) Angiographic estimation of righ ventricular volume in man. Circulation 50: 324-330.

12. Chobanian AV, Bakris GL, Black HR, Cushman WC, Green LA, et al. (2003) Seventh report of the Joint National Committee on Prevention, Detection Evaluation, and Treatment of High Blood Pressure. Hypertension 42: 1206-1252. 
Citation: Abdeltawab A, Eweda I, Mostafa AE, Demian P, Awwad O (2018) Relation of RV Function to Presence and Degree of Systemic Hypertension. J Cardiovasc Dis Diagn 6: 306. doi: 10.4172/2329-9517.1000306

13. Ferlinz J (1980) Right ventricular performance in essential hypertension Circulation 61: 156-162.

14. Cicala S, Galderisi M, Caso P, Petrocelli A, D’Errico A, et al. (2002) Right ventricular diastolic dysfunction in arterial systemic hypertension: Analysis by pulsed tissue doppler. Eur J Echocardiogr 3: 135-142.

15. Akintunde AA, Akinwusi PO, Opadijo OG, Familoni OB (2010) Effect of systemic hypertension on right ventricular morphology and function: An echocardiographic study. Cardiovasc J Afr 21: 252-256.
16. Myslinski W, Mosiewicz J, Ryczak E, Barud W, Bilan A, et al. (1998) Right ventricular function in systemic hypertension. J Hum Hypertens 12: 149-155.

17. Nishimura RA, Abel MD, Hatle LK, Tajik AJ (1989) Assessment of diastolic function of the heart: Background and current applications of Doppler echocardiography. Part II. Clinical studies. Mayo Clin Proc 64: 181-204.

18. Cittadini A, Fazio S, Stromer H, Cuocolo A, Sabatini D, et al. (1995) Optimal determination of right ventricular filling dynamics in systemic hypertension. Am Heart J 130: 1074-1082. 